\title{
Hypnotherapy and the Bhagavad Gita
}

\author{
Shaunak A. Ajinkya ${ }^{1}$, Deepali S. Ajinkya ${ }^{2}$, Gurvinder Kalra ${ }^{3}$
}

\section{ABSTRACT:}

Indian history is one of the most ancient in the world; replete with many wars, teachings and religious beginnings. Hinduism is one of India's most prominent religions with the Bhagavad Gita being one of its most significant scriptures. Many authors have postulated that different psychotherapeutic methods have been used and described in Bhagavad Gita. In this article, we have explored regarding descriptions of the possible use of hypnotherapy in this holy text.

Keywords: Hypnotherapy, Hypnosis, Psychotherapy, Bhagavad Gita, Hinduism

India is a country with a varied and rich mythology. Its ancient history is replete with many wars, teachings and religious beginnings. Hinduism is one of India's most prominent religions with the Bhagavad Gita being one of its most significant scriptures. The Bhagavad Gita contains philosophical discussions between prince Arjuna and Lord Krishna on the battlefield of Kurukshetra. Followers of Hinduism look upon the Bhagavad Gita as the most revered text which guides them in their difficult times. It has been postulated by various authors that different psychotherapeutic methods have been used and described in Bhagavad Gita (Reddy, 2012; Vaishnav, 2009; Rao and Parvathidevi, 1974; Satyananda, 1972; Jeste and Vahia, 2008; Hegde, 2009; Balodhi and Keshavan, 2011). We conducted a literature search and identified papers and texts which we perceived to be relevant. In this review article, we have explored regarding descriptions of the probable use of hypnotherapy in this holy text.

${ }^{1}$ MD, DPM, Professor, Department of Psychiatry, MGM Medical College \& Hospital, Navi Mumbai, India

${ }^{2}$ MBBS, DPH, Director, MYM Institute of Clinical Hypnosis, Mumbai, India

${ }^{3}$ MD, DPM, Staff Psychiatrist, Flynn Adult Inpatient Psychiatric Unit, La Trobe Regional Hospital Mental Health Services (LRH-MHS) Traralgon, Victoria 3844, Australia 


\section{Hypnotherapy and the Bhagavad Gita}

\section{HYPNOSIS AND HYPNOTHERAPY}

Hypnosis is a method by which a person can be guided into an altered state of consciousness called the trance state. It is characterized by a deep state relaxation with increased suggestibility. In this state, one may achieve physical and psychological changes that are seemingly beyond one's normal conscious capability. For most people it is a pleasant state of deep inner calm and physical relaxation. Anyone who is willing to cooperate and follow simple instructions can be hypnotized. The state of deep trance is similar to that experienced by experts in yoga and practitioners of various meditation techniques (Kroger, 2008).

As a matter of fact, each one of us is using hypnosis, knowingly or unknowingly in some form or the other, every single day of our lives. We experience a trance-like state each time we are lost in thoughts, lose track of time or engage in day-dreaming. The people that are easiest to hypnotize are those who are able to maintain focus on a desired objective (Kroger, 2008).

Psychological therapy done in conjunction with the hypnotic trance state is called as hypnotherapy. It is often classed as a form of complementary medicine but is perhaps better viewed as a branch of psychotherapy. It is not an occult esoteric art but a science-based therapeutic discipline. Utilizing the state of deep trance, the therapist assists the client in uncovering and exploring thoughts, emotions and memories of past events which may have been affecting a person's present state of mind. By activating one's own inner resources, hypnotherapy has been known to help in psychological and psychosomatic disorders. Besides this, hypnotherapy can be used to help replace negative thoughts with positive affirmations for personal growth and development (Kroger, 2008).

A lot of people believe that when they are hypnotized they will not be aware of anything that is happening around them. Yet, if one lost all connection with the hypnotist, how would one be able to follow the instructions given by therapist? Hypnosis has absolutely nothing to do with being asleep or being unconscious. One hears everything and knows what's going on during the entire process (Erickson, Seymour and Secter, 2005). Thus all hypnosis is ultimately selfhypnosis. A person is always in control and it is always up to the person, whether he/she wants to accept or reject the ideas and statements offered by the therapist (Elman, 1968). 


\section{Hypnotherapy and the Bhagavad Gita}

\section{CHARACTERISTICS OF THE HYPNOTHERAPIST}

Like other therapists, a hypnotherapist also needs to have certain characteristics that can help him/her be a better therapist. An ability to form a good rapport with the client is the foremost pre-requisite. The therapist also needs to be truthful, empathetic, non-judgmental and an active listener. Proper training and experience with psychotherapy is an important pre-requisite for being a good hypnotherapist (Aisling and Ray, 2010).

\section{STAGES OF HYPNOTHERAPY SESSION}

There are five stages to any hypnotherapy session (Kroger, 2008):

1. Induction - done by focusing on an object/word(s), by progressive muscular relaxation or reverse counting. The main aim is to induce focused attention.

2. Deepening - The purpose is to develop the trance state further so that the client becomes more suggestible.

3. Suggestions - The main work of hypnosis is carried out here. Techniques like creative visualization and positive suggestions are used.

4. Post-hypnotic suggestions - Suggestions that are given to client under hypnotic trance, which then later on affect his behavior in the desired manner after the individual comes out of trance.

5. Awakening - the individual is roused from his state of trance.

However, these five stages of hypnosis are not always necessary to accomplish the goals of hypnotherapy and one may achieve the desired effects without the help of the trance state. This is known as waking hypnosis. In certain people who are extremely suggestible, every effect that is possible using the trance state can also be obtained with waking hypnosis. The key to this process is that the mind of the client must lock itself around a given idea. For example, the crying child is certain that if the mother kisses him/her then the pain will disappear. To cause the mind to lock around a given idea, the suggestions must be given with complete confidence and absolute assurance, leaving no room for doubt. An emotionally disturbed client is usually hypersuggestible. Waking hypnosis is usually used when there is very little time to achieve the trance state or when, for some reason, there is resistance to it. It can also be achieved in patients who have never formally experienced the trance state before (Elman, 1968). 


\section{Hypnotherapy and the Bhagavad Gita}

\section{HYPNOSIS IN ANCIENT INDIA}

Hypnosis in Indian history is known as 'Sammohana' which was part of Yoga Vidya (science of yoga) and has been practiced in India since Vedic times. Many yogis and sages practiced selfhypnosis during meditation to still their minds. It was also known as Pran vidya or Trikaal vidya and was at its peak during the Aryan era (circa 1500-500 B.C.). The evidence of the use of sammohana is found in ancient texts like the Bhagavat Purana in which Lord Vishnu in his Mohini avatar illudes the asuras (demons) to procure the amrit kumbh (pot of nectar) and gives it to devas (gods) (Swami Prabhupada, 1999). Even the Atharvaveda, one of the four principal sacred texts of Hinduism, has passing reference to hypnosis and suggestions e.g. "Touching you with these two hands and ten fingers, by my influential speech I speak to you, disease removing words. By this you will get health and all your diseases will vanish." (Atharvaveda 4:13:7) (MaxMuller and Bloomfield, 2004).

These evidences suggest that hypnosis was probably in use in ancient India. Since Lord Krishna, one of the characters in Mahabharata was well versed with the ancient scriptures, it is probable that he may have used this knowledge to help Arjuna, the warrior, who was in acute distress (Naik, 2006). The word Sanskrit word for hypnotism is sammohana. Lord Krishna is also known as Mohana, which means the one who hypnotizes or enchants others. He has been described as playing enchanting tunes on his flute because of which all the women-folk and the gopis (cowherds) of Vrindavan (a place where he spent his childhood) would gather around him (Swami Prabhupada, 1999).

\section{THE BHAGAVAD GITA}

The Bhagavad Gita is a sacred Hindu scripture, comprising of 18 chapters and 700 verses and is a part of the ancient Sanskrit epic of Mahabharata. This scripture contains a conversation between Pandava prince Arjuna and Lord Krishna on a variety of philosophical issues. Faced with a fratricidal war, on the battlefield Arjuna refuses to fight and helplessly turns to his charioteer Lord Krishna for counsel. In such a situation there was need to stimulate Arjuna into battle. Lord Krishna, as written in the Bhagavad Gita, not only imparts spiritual knowledge to Arjuna but also is able to quickly convince him to fight the war (Swami Prabhupada, 1983). Reading the Bhagavad Gita one can find references that suggest the use of hypnotherapy (using modern-day waking hypnosis) and following is a brief discussion of the same. 


\section{Hypnotherapy and the Bhagavad Gita}

\section{Arjuna's hypersuggestible state}

The first chapter, Arjuna Vishad Yoga, describes the emotional experiences of Arjuna within the battlefield when he sees his own kith and kin lined up in opposition for a war. He is described as feeling sad, sorrowful, anxious, fearful and guilty. Arjuna says, "My dear Krị̦hṇa, seeing my friends and relatives present before me in such a fighting spirit, I feel the limbs of my body quivering and my mouth drying up. My whole body is trembling, my hair is standing on end, my bow, the Gạṇ̣̂va, is slipping from my hand, and my skin is burning. I am now unable to stand here any longer. I am forgetting myself, and my mind is reeling. I see only causes of misfortune...." (BG 1:28-30) ${ }^{1}$ (Swami Prabhupada, 1983). "Arjuna having thus spoken this on the battlefield cast aside his bow and arrows and sat down on the chariot, his mind overwhelmed with grief leading him into inaction” (BG 1:46) (Swami Prabhupada, 1983).

Such highly emotionally charged states can make a person hyper-suggestible which is a prerequisite for any hypnotherapeutic intervention (Kroger, 2008).

\section{Lord Krishna's authoritative position}

Lord Krishna was not only Arjuna's good friend but also his philosopher and guide. Arjuna asks Lord Krishna for advice and surrenders his will unto him. Arjuna says, "Now I am confused about my duty and have lost all composure because of miserly weakness. In this condition I am asking you to tell me for certain what is best for me. Now I am your disciple, and a soul surrendered unto you. Please instruct me.” (BG 2:7) (Swami Prabhupada, 1983).

To increase the effectiveness of hypnotherapeutic suggestions it is vital for the therapist to be in a position of authority in order to form good and lasting rapport with the client. Arjuna's total surrender to Lord Krishna puts the latter in an authoritative position to change Arjuna's distorted belief system (Elman, 1968).

\section{Induction and use of indirect suggestions}

Induction in hypnosis is done by focusing on an object/word(s), the main aim being to induce focused attention. In chapter 2 of the Bhagavad Gita, Lord Krishna instructs Arjuna gently to 'focus on the true inner self' and to become free from anxieties of gain and safety (BG 2:41-46). (Swami Prabhupada, 1983;Vartak, 1990). After this that Arjuna subsequently leaves his worries behind and commits himself to the task at hand (Swami Rama, 2004).

\footnotetext{
${ }^{1} \mathrm{BG}$ : Bhagavad Gita; the $1^{\text {st }}$ number in parenthesis refers to the chapter number while the later digits refer to the verse numbers.
} 


\section{Hypnotherapy and the Bhagavad Gita}

Indirect Associative Focusing is a technique made famous in modern times by Dr. Milton Erickson. It is used for induction of the hypnotic state in which the therapist raises relevant topics without forcing them on to the client. This in turn allows the client to make his own decisions regarding following further suggestions from the therapist (Erickson, Seymour and Secter, 2005).

\section{Use of visualization and imagery}

Creative visualization is the basic technique underlying positive thinking in which the individual is encouraged to envision the desired goal beforehand. A detailed schema is created of what one desires and then the end result is visualized over and over again (Roeckelein, 2004). In chapter 11, Arjuna admits that he is convinced by Lord Krishna's philosophy (BG 11:1). He wishes to see Lord Krishna's Vishwaroop (Universal Form) (BG 11:2-4). Then Krishna gives a direct authoritative instruction to Arjuna, 'See now my opulence, hundreds of thousands of my divine forms' (BG 11:5). Later Krishna says, "But you cannot see me with your present eyes, therefore I give you divine eyes" and goes on to describe to Arjuna in following verses what the latter should 'see' (BG 11:6-7). He exhorts Arjuna to get up, fight and vanquish his enemies as they 'have already been destroyed by him' (BG 11:33-34) (Swami Prabhupada, 1983). This suggests that Lord Krishna used a creative visualization technique in the context of "the enemies already having been destroyed" (Vartak, 2005).

\section{Arjuna's altered state of consciousness}

In chapter 11, Arjuna gets awed and terrified by visualizing Krishna's vishwaroop, and requests him to show his original form (BG 11:45). Responding to this request Lord Krishna changes the visualization saying, "You have been perturbed and bewildered.... Now let it be finished... With a peaceful mind you can now see the form you desire" (BG 11:49). Later Arjuna says, "Seeing your original form I am now composed in mind and I am now restored to my original nature" (BG 11:51) (Swami Prabhupada, 1983). According to these statements it may be inferred that Arjuna was in an altered state of consciousness, characteristic of a trance-like state (Kroger, 2008; Vartak, 2005).

\section{Post hypnotic suggestion and awakening}

Post hypnotic suggestion is a suggestion given to a client under hypnosis which affects his behavior in a desired manner after the hypnosis session. Posthypnotic suggestions may be for an action, a feeling or an internal physical change to occur. It helps to increase adherence to therapy and to carry out assigned tasks (Erickson, Seymour and Secter, 2005). In the concluding chapter, 


\section{Hypnotherapy and the Bhagavad Gita}

Lord Krishna instructs Arjuna to shed all his anxieties and adopt a complete fearless state. He tells him not to worry and to leave everything onto him and trust him (BG 18.66) (Swami Prabhupada, 1983).

Therapies are generally considered successful when their predetermined goals are achieved. In this context, Lord Krishna's aim was to reduce Arjuna's fears and prepare him to fight the battle. ${ }^{[1]}$ To confirm this transformation in Arjuna, Lord Krishna asks in the last chapter of the Bhagavad Gita, whether Arjuna's "ignorance and illusions are now dispelled" (BG 18:72) (Swami Prabhupada, 1983). Thereafter, Arjuna admits to being convinced and as per Lord Krishna's instructions, gets ready to fight the battle (BG 18.73) (Swami Prabhupada, 1983). Thus

Lord Krishna changes Arjuna's fearful and anxious state to a fearless one, by which Arjuna who initially was ready to give up all his duties, decides to fight the battle till the end.

\section{CONCLUSION}

The Bhagavad Gita describes the interactions between Lord Krishna and Arjuna, whereby the former is in the role of a therapist. Lord Krishna who was revered by Arjuna convinces him to change his belief system later reinforced by creative visualizations. With the help of instructions he guides Arjuna into acting out on the suggestions given. This implies that the steps followed in modern-day hypnotherapy may have its actual roots in ancient scriptures like the holy Bhagavad Gita.

\section{REFERENCES}

Aisling, K., \& Ray. M. (2010). Accomplish Change. Qualities to look for in a hypnotherapist. Retrieved October, 2012, from http://accomplishchange.ie/blog/2010/08/06/qualities-tolook-for-in-a-hypnotherapist/

Balodhi, J. P., \& Keshavan, M. S. (2011). Bhagavad Gita and Psychotherapy. Asian J Psychiatry, 4, 300-302.

Elman, D. (1968). Hypnotherapy. Los Angeles: Westwood Publishing Co.

Erickson, M. H., Seymour, H., \& Secter, I. (2005). The Practical Application of Medical and Dental Hypnosis. Florida: OTC Publishing Corp.

Hegde S. (2009). National seminar on Bhagavad Gita and mental health: Conference proceedings. Asian J Psychiatry, 1, 60. 


\section{Hypnotherapy and the Bhagavad Gita}

Jeste, D. V., \& Vahia, I. V. (2008). Comparison of the conceptualization of wisdom in ancient Indian literature with modern views: Focus on Bhagavad Gita. Psychiatry, 71, 197-209.

Kroger, W. S. (2008). Clinical and experimental hypnosis (2nd ed.). Philadelphia: Lippincott, Williams and Wilkins.

Max-Muller, F., \& Bloomfield, M. (2004). Hymns of the Atharva Veda-Sacred Books of the East Part Forty Two. Montana: Kessinger Publishing.

Naik, M. (2006). Hypnotisamche Samarthya. Mumbai: Jai Vikas Prakashan.

Rao, V. A., \& Parvathidevi, S. (1974). The Bhagavad-Gita treats body and mind. Indian J Hist Med, 19, 34-44.

Reddy, M. S. (2012). Psychotherapy - Insights from Bhagavad Gita. Transcultural psychiatry, 34, 100-104.

Roeckelein, J. E. (2004). Imagery in Psychology: A Reference Guide. Connecticut: Greenwood Publishing.

Satyananda, D. (1972). Psychology of the Gita of Hinduism. London: Oxford and I.B.H.

Swami Prabhupada. (1983). Bhagavad Gita As It Is. International Society for Krishna Consciousness. Mumbai: The Bhaktivedanta Book Trust.

Swami Prabhupada. (1999). Śrimmad Bhāgavatam. International Society for Krishna Consciousness. Mumbai: The Bhaktivedanta Book Trust.

Swami Rama. (2004). Perennial psychology of the Bhagavad Gita. Philadelphia: Himalayan Institute Press.

Vaishnav, M. (2009) Spirituality and psychiatry: complementary or contradictory- based on Bhagavad Gita. In Sharma, A. (Ed.). Spirituality and mental health: reflections of past, applications in present, projections for future. Indian Psychiatry Society.

Vartak, P. V. (1990). The Gita. Pune: Vartak Prakashan.

Vartak, P. V. (2005). Yugpurush Shri Krishna. Pune: Vartak Prakashan. 